\title{
Vignettes: a data collection technique to handle the differential operation of items in surveys
}

\author{
Antonio Sergio Silva ${ }^{1, t}$ (D) \\ ${ }^{1}$ Universidade de São Paulo, São Paulo, SP, Brazil \\ Wilerson Lucas Campos-Silva ${ }^{2, \Omega} \mathbb{B}$ \\ ${ }^{2}$ Universidade de São Paulo, São Paulo, SP, Brazil \\ Maria Aparecida Gouvea ${ }^{3,}:($ (D) \\ ${ }^{3}$ Universidade de São Paulo, São Paulo, SP, Brazil \\ Milton Carlos Farina $4, \neq$ (D) \\ ${ }^{4}$ Universidade Municipal de São Caetano do Sul, São Caetano do Sul, SP, Brazil
}

\section{ABSTRACT}

Vignettes are scenarios used in many areas of academic research, whose main application is related to situations in which judgments about people are subject to biases or distortions. Despite the wide use of vignettes in surveys, the recommendations for their creation are limited in the literature. Thus, this study aims to review and describe criteria presented in the literature for robust textualization of vignettes. This study presents a literature review on the use of vignettes and describes a minimum set of criteria (plausibility, clarity, simplicity, content validity and analogy between the vignette and the construct) for the judicious application of this methodology. They have presented four vignettes constructed from the literature review and validated by panel of experts, with the purpose of capturing the perception of respondents on the protagonists' actions in scenarios about co-creation value in a health service. In this way, the study conceives the essential elements for the development of this methodology.

Keywords: Vignettes, Scenarios, Data collection, Surveys, Differential item functioning.

\section{INTRODUCTION}

In surveys, it is common to ask people to answer questions about health, policies, job satisfaction, life satisfaction, etc. For example, consider the question: "How are you satisfied with your life?". In general, the researcher provides the informant with a scale whose responses can range from "very dissatisfied" to "very satisfied". If the objective of the research is to analyze the real differences between the groups, the direct answers to the self-assessments of the respondents may be biased, since they can interpret the categories of responses in different ways. This heterogeneity in the behavior of informing on survey responses, also called differential item functioning (DIF), reflects an interpersonal incomparability (VOŇKOVÁ; HULLEGIE, 2011).
Corresponding author:

† Universidade de São Paulo, São Paulo, SP, Brazil

E-mail: ansesi@usp.br

${ }^{\Omega}$ Universidade de São Paulo, São Paulo, SP, Brazil

E-mail: willerson.silva@usp.br

${ }^{¥}$ Universidade de São Paulo, São Paulo, SP, Brazil

E-mail:magouvea@usp.br

‡ Universidade Municipal de São Caetano do Sul, São Caetano do Sul, SP, Brazil

E-mail:milton_farina@uol.com.br

Received: 08/17/2017.

Revised: 08/02/2018.

Accepted: 03/22/2018.

Published Online: 10/03/2018 
An approach to dealing with DIF in surveys was proposed by King et al. (2004). The authors introduced vignettes, which are brief descriptions of hypothetical situations about people's lives, and which are important for a certain domain of interest. The concept implies that the respondent evaluates both the situation of the person in the hypothetical description and his/her own position in relation to the scenario (EVANS et al., 2015; GROLPROKOPCZYK; FREESE; HAUSER, 2011). Given that the same scenario is presented to several people, similarly, the evaluation of vignettes can provide information on respondent styles (VONKKOVÁ; HULLEGIE, 2011).

In spite of the use of vignettes in surveys, such as in the health area (CHRISTEN, HILTON et al., 2016, OREMUS, XIE, GAEBEL, 2016, SILVA et al., 2015, WINSOR, MCLEAN, 2016), in Sociology (CHRISTEN et al, 2016; GANONG; JAMISON; Chapman, 2015) and empirical research in marketing (COVA; PARANQUE, 2016; ZHANG; SIMON, 2016), the recommendations for its establishment are limited in the literature (WASON; POLONSKY; HYMAN, 2002). Thus, this study aims to review and describe criteria presented in the literature for robust textualization of vignettes.

\section{DIFFERENTIAL FUNCTIONING OF ITEMS}

Psychometrics recognize the need and importance of standardization of the conditions of application of measurement instruments, one of the most important assumptions of the evaluation. In relation to the conditions of application of measurement instruments, an area of the item response theory dedicates to its study through DIF (ANDRADE; LAROS; GOUVEIA, 2010; ANDRIOLA, 2001).

The presence of DIF in measurement instruments leads to lack of equity in evaluation processes (GROL-PROKOPCZYK; FREESE; HAUSER, 2011). For example, consider a situation in which two groups of people are submitted to a five-item assessment, whose base text is about football. Group A, made up of female people, did not match any item, while people in group B, made up of males, matched all items. The hypothesis arises, that the items on soccer would favor the male, to the detriment of the female people. It is inferred, therefore, that the items have DIF. The DIF, in other words, is an empirical evidence that the subgroups do not present the same probability of correctness in the item (ANDRADE; LAROS; GOUVEIA, 2010; ANDRIOLA, 2001; GROL-PROKOPCZYK; FREESE; HAUSER, 2011).

Studies on DIF have been widely used to reduce the effects of incomparability among people in surveys. Researchers try to improve the problems of interpersonal and transcultural incomparability in surveys through careful questioning, translation (retranslation), focus group, prior cognitive information, and other techniques (KING; WAND, 2007).

Among these, anchoring by vignettes is a technique developed to improve the problems that occur when different groups of respondents interpret and use the responses of an ordinal scale (for example, from full approval to complete disapproval) in a varied way (KING et al., 2004). The anchorage with vignettes addresses DIF by introducing supplementary questions so that we are able to construct a common scale of measures through respondents (KING; WAND, 2007).

For King et al. (2004), the objective of constructing a survey through vignettes is not to create DIF-free questions, but to find consistency in responses and equivalence in vignettes. Therefore, a vignette must be written to describe, in a clear and concrete language, the character's status to the point where the respondent positions himself/herself in all situations 
BBR

16,1

and is able to compare his/her own status with the character's status (EVANS et al. KING et al., 2004). The next section provides a review of what vignettes are, as well as arguments that justify their superiority to the use of direct questions in surveys.

\section{VIGNETTES}

A scenario is a story that presents a hypothetical situation that demands action or judgment from the respondents (WASON; POLONSKY; HYMAN, 2002). Likewise, a vignette is a brief description of a person or a social situation that contains precise references to what is believed to be the most important factors for the respondent to make a decision or make a judgment (WASON; POLONSKY; HYMAN, 2002).

Because they are stimuli used to collect data in surveys, like any other research tools, vignettes must be designed properly, otherwise they will produce invalid data. The simple adaptation of previously published scenarios can be a problem for the researcher, especially if the original research presents faults in its constructions. Any changes in the context of the scenarios can have different effects on the study variables (WASON; POLONSKY; HYMAN, 2002).

The vignettes emerge as an analog research model. This type of research constitutes a reasoning through an example. As opposed to in vivo research, whose factors the researcher cannot manipulate or control, in analogical research we are able to control the variables of interest (LANGER, 2016).

Analog research can be done through live models, audio or video recordings, or written descriptions of a customer encounter. Written scenarios are also termed as vignettes. A set of vignettes can be evaluated over a relatively short period of time by the respondents (HEVERLY; FITT; NEWMAN, 1984). In a set of five or more vignettes, for example, it is possible to incorporate several factors into each vignette and study them simultaneously. An additional advantage in using vignettes relates to the customer's first impression bias, such as physical appearance, dressing, speech, etc., being free from such bias (HEVERLY; FITT; NEWMAN, 1984).

Wason, Polonsky and Hyman (2002) identified six arguments in the literature that justify the superiority of vignettes in relation to research with direct questions. For these authors, a vignette: (a) provides greater realism because it provides a variety of situational or contextual factors; (b) provides a standardized stimulus for all respondents, which increases internal validity, measure reliability, and ease of replication; (c) improves the validity of the construct because it directs the attention of the respondent to specific aspects of the research problem question; (d) it transposes difficulties, such as time and expenses, to study real business decisions; (e) reduces the social convenience bias, especially if the questions about the intention to behave are written in the third or first person; and (f) increases the involvement of respondents and dramatizes the issues.

As an example, Figure 1 represents two self-assessments (respondents 1 and 2) and three vignettes (characters 1, 2 and 3) regarding the level of difficulty in practicing physical activities. The degree of self-assessment of the level of difficulty in practicing physical activity is lower for respondent 1 than respondent 2 (and both agree on the ordering of the difficulty level of the characters).

Following is a review of the recommendations on the construction of vignettes. 


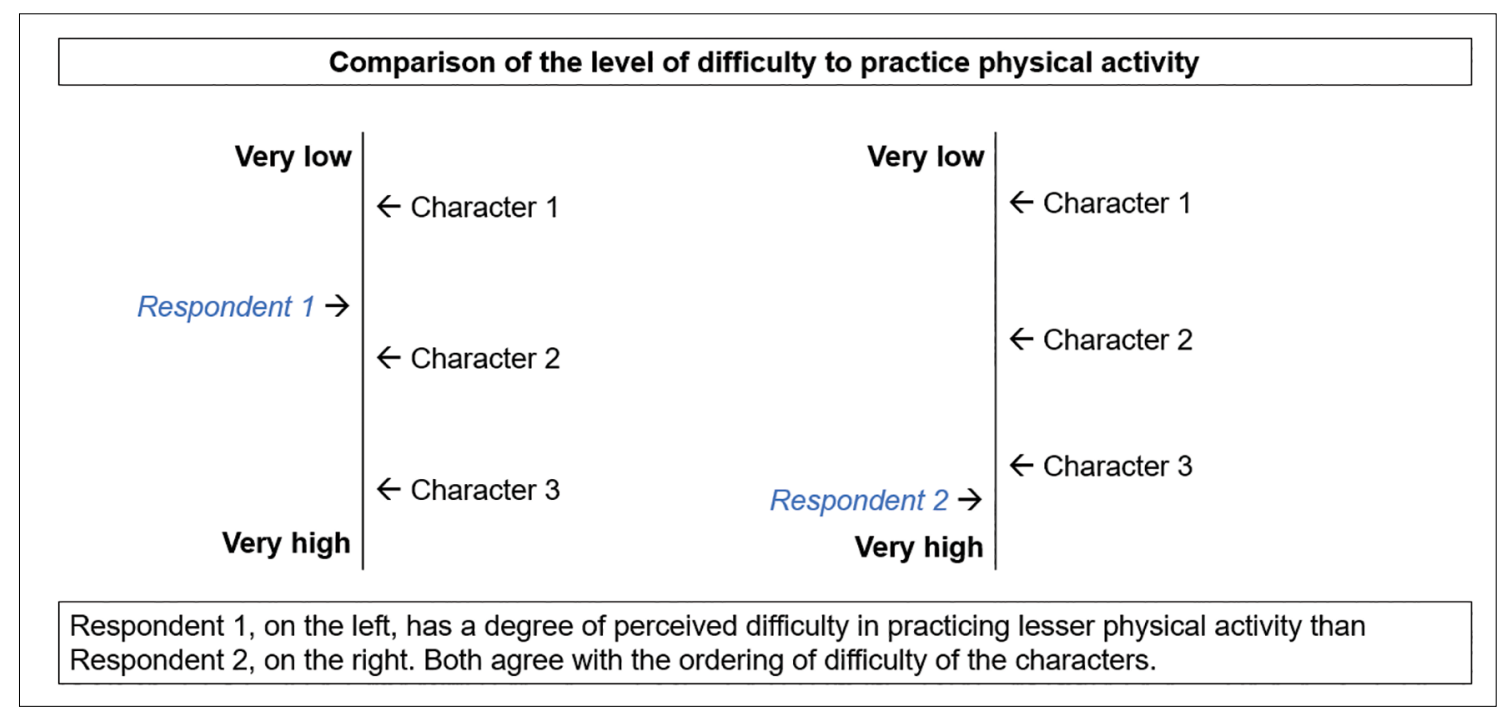

Figure 1. Response scale, vignette technique. Source: based on King et al. (2004).

\section{CONSTRUCTION OF VIGNETTES}

The greatest challenge in the construction of vignettes is to strike a balance between the rigor of the experimental method and the reality of the environment they describe. An ideal set of vignettes should present a descriptive summary that resembles the real case stories and whose variation exists only in the factors studied (EVANS et al., 2015, LANGER, 2016). A vignette should be short and informative, and reflect an average level of operation, so that there is enough variance to reveal the influence of each factor studied (LANGER, 2016). The set of factors should be small and avoid sensitive topics such as rape, suicide, euthanasia, etc., as they distort the assessment and position people's responses at the extremes of the response scale (HEVERLY; FITT; NEWMAN, 1984).

According to King et al. (2004), the respondent does a self-assessment and evaluation of several hypothetical people described in vignettes. Vignettes are arranged on an ordinal scale, from the most effective to the least effective. The authors recommend that the self-assessment of the respondent be positioned at the end of the scenarios. The authors' approach assumes two key assumptions: consistency of response and vignette equivalence.

The consistency of the response assumes that each person uses the category of responses to a particular question of the survey the same way, whether in self-assessment or evaluation of hypothetical situations. The type of DIF can vary between respondents and even for a single respondent among the questions of a survey, but it cannot vary between the selfassessment and the set of vignettes associated with a single question for any respondent. This property can be violated if the respondent feels inferior in relation to the hypothetical situation (KING et al., 2004).

The equivalence of vignette assumes that all respondents perceive the level of the variable represented in any vignette in the same way, on the same one-dimensional scale, independent of the random error. Respondents may differ in how they perceive the level of variation established in vignettes, but any difference is random and independent of the characteristic being measured. This premise can be violated if the respondent interprets the writing of some vignette as directed to some particular interest of the researcher (KING et al., 2004). 
BBR

16,1

\subsection{THE RESPONDENT}

The respondent can provide information both inside (insitu) and outside (exsitu) of a real situation. Insitu, therefore, refers to the information about the respondents coming from real situations, created and documented in situations of use. Exsitu, on the other hand, concerns the seizure of information outside the actual use situations, either retrospectively or in advance (EDVARDSSON et al., 2012). In each specific context, it creates values in different ways, according to its intention and competence. In relation to the context dimension, we can obtain information from people who have had (in context) or not (ex context) a real contextual experience (EDVARDSSON et al., 2012).

Figure 2 illustrates how these two dimensions, from the perspective of Edvardsson et al. (2012), classify respondent participation to generate information.

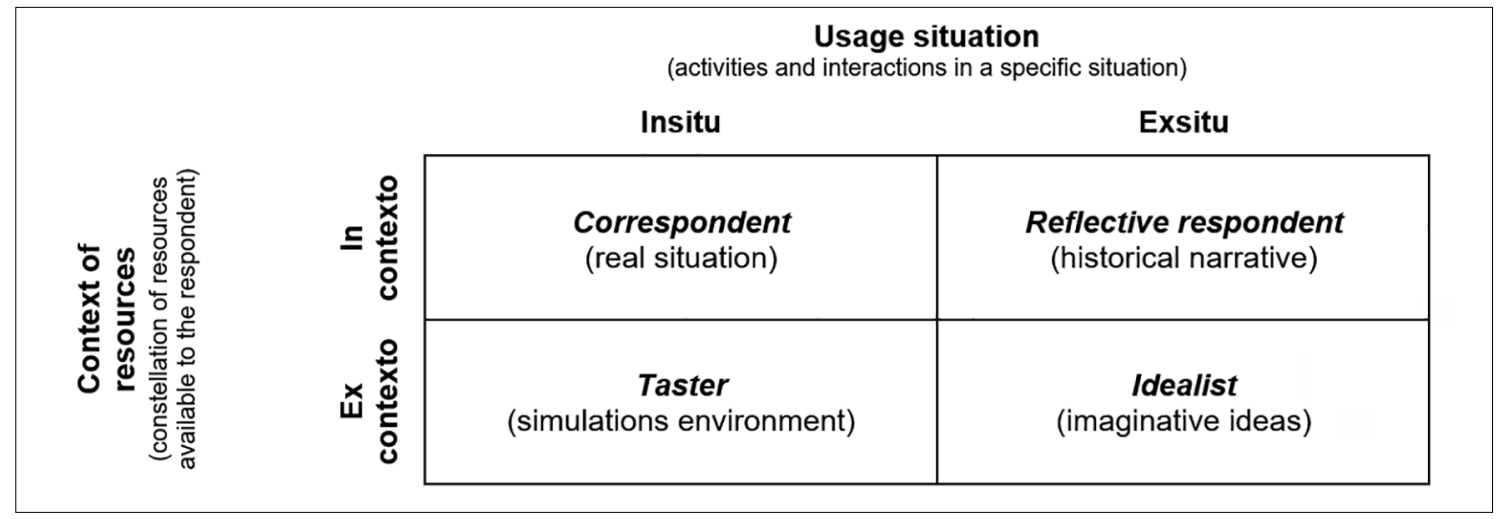

Figure 2. Framework for identifying methods of using customer information in service creation. Source: based on Edvardsson et al. (2012).

Vignettes are analogous to the reflective or idealistic respondent roles proposed by Edvardsson et al. (2012). We anchor the reflective respondent's mode in the context experience of a real resource. The information generated by the methods that involve this mode provides valid information from respondents who are familiar with the context of the resources. Thus, we generate the information after a real situation has occurred and, in this way, the respondents have the opportunity to reflect on what happened (EDVARDSSON et al., 2012).

\subsection{VALIDITY AND RELIABILITY OF VIGNETTES}

For Heverly, Fitt and Newman (1984) the construction of vignettes that describe reality and are valid requires:

a. Identification of the constructs of interest. The first step is to create a blueprint that identifies the constructs of interest that are to be transformed into vignettes, as well as their evaluation levels. The constructs should be selected from a literature review.

b. Creation of components of vignettes. It identifies sources from which the descriptions representing the constructs are derived. This can be done by reviewing the empirical literature or by consulting experts. Regardless of the approach, empirical validation by an independent sample of judges is required. 
c. Validation of vignettes components. The components of vignettes are classified to determine which represent the constructs that are proposed to represent. Those that are validated form the final set that will compose a vignette.

d. Construction of the vignettes from their components. The components of the vignettes should be randomly distributed so that they counterbalance all the research factors.

In addition to conventional methods to ensure the validity and reliability of surveys, such as pre-testing and validation by a panel of experts, attention is drawn to the following aspects regarding the use of vignettes (WASON; POLONSKY; HYMAN, 2002):

a. Plausibility. The researcher must evaluate and adjust the internal consistency and verisimilitude of vignettes. The vignettes pre-test can ensure that respondents actually believe that the simulations are realistic and consistent.

b. Suitability. The detailing of vignettes should be sufficient to control as much as possible the idiosyncratic projections of the respondents, but without becoming excessively long to the point of overloading them.

c. Tonality. The greater or lesser detailing of a vignette should be consistent with the research problem.

d. Truism. The manipulated variables must be constructed in a clear and evident way and that the respondent, therefore, does not overlooked it.

e. Formulation. The framing of a vignette influences the responses. Different versions must be formally equivalent, so that any variation in textualization does not change the objective information or the respondent's perception.

It is also important to evaluate the validity and generalization of the evaluation of the results obtained with vignettes. The validity of content refers to the semantic correspondence between the conceptual definition of the construct and its measure. A fully valid content means that there is a semantic identity between the construct and the measure. In other words, the measure accurately represents what the construct proposes to define (ROSSITER, 2011).

Wason, Polonsky and Hyman (2002) describe potential problems or deficiencies when considering the use of vignettes, which are:

a. Selection of suitable method for vignette. Many surveys done with vignettes are based on the constant-variable-value-vignette method (CVVV), that is, all respondents analyze the same vignette. Some disadvantages may arise from this methodology: divergence in the perception of the alternatives of evaluation among the respondents, the answers do not describe the sequence of thoughts that the respondent used to evaluate the behavior, a set of fixed items may omit other important items of the construct, besides the bias of social convenience.

b. Adapt the questions to the vignettes. Previously validated scales are preferred over new ones. On the other hand, one should not rely entirely on pre-existing vignettes. The researcher should ensure that the questions thoroughly explore the relevant issues of his/her study and look for the presence of DIF.

c. Certification of the use of all relevant variables. Initially, the researcher must identify the dimensions, then the various levels included in each dimension and that can affect the judgment or the decision. 
BBR

16,1

d. Use the appropriate number of vignettes. Few vignettes can limit the researcher's ability to manipulate critical variables. A large number of vignettes, on the other hand, can lead to information overload and respondent fatigue.

e. Control of social convenience bias. The use of vignettes, textualized in the third person, projects the respondent into the position of the character and can reduce this bias. The use of the first person may introduce an attribution error because people tend to believe they have more control over the situation than the characters.

f. Appropriate population survey. The researcher should select respondents who can give meaningful answers to all vignettes.

g. Adequacy of vignettes for respondents. The researcher should ask for eventual respondents of the population to disclose relevant situations that involve the study variables and can be done in a qualitative way in a focus group, for example.

h. Application of joint analysis with a theoretical and practical platform. The essential question is to establish a set of attributes and their levels. For Malhotra (2008) the attributes must be: determinants; easy to measure and communicate; realistic; compensatory; arranged so that one level is preferable to another level; as a whole, it must properly define the situation chosen; and should not be redundant.

It is also important that respondents do not perceive the results as a personal threat. Conducting a poorly conducted survey with vignettes can bring more harm than good. Special attention should be paid so that situations do not arise that affect the morality of the respondents (HEVERLY; FITT; NEWMAN, 1984).

Regarding the judgment of specialists, Rossiter (2011) recommends a sample with three experts, five managers with less education or ten respondents with less education to carry out an initial pre-test to choose the items of the questionnaire and the format of the answers.

McCrow et al. (2013) proposed a questionnaire to assist researchers in creating vignettes with reliable analogies of the desired clinical scenarios. The questionnaire was applied to the experts with characteristics of "blind and independent review". These should rank in order (ranking) the items clarity and simplicity, and make a discrete choice between plausibility of content, content validity and analogy of vignette with the construct. A modification of the checklist proposed by McCrow et al. (2013) can be seen below, in the results section, in Figure 5.

There is no consensus on the adequate number of vignettes in a survey (BACHMANN et al., 2008). Some studies, however, suggest that as the number of attributes, choices, and vignettes increases, the reliability of the response decreases. In general, the number of attributes in a vignette should not exceed eight (LOUVIERE; EAGLE; COHEN, 2005) and the number of vignettes should not exceed twenty (JOHNSON; ORME, 1996). The next section describes the methodology applied in this study.

\section{METHODOLOGY}

In this section, we present the development of an application of the method for creating vignettes to a survey of value co-creation in health services. It should be noted, that this study does not aim to demonstrate how vignettes minimize the effects of DIF in surveys. For this, we recommend a review of the study by King et al. (2004), where such authors demonstrate these properties. The research proposes to identify elements of the literature 
that contribute to the robust construction of vignettes, whose nature approaches a more prescriptive rather than descriptive approach to the method.

Initially, we construct a blueprint in the model of structural equations modeling to propose a hypothetical model considering the constructs flexibility, responsiveness and coinnovation of the front-line employees of a health service who are positively associated with the value creation construct (SILVA et al., 2015).

Each construct has a cluster of evaluation items (measurement model) that were the objects of the survey. The flexibility construct, for example, has six items. We apply the final questionnaire with the 4 vignettes and the 27 items to the model that will be presented in Figure 3 (SILVA, 2014). However, details regarding structural equation modeling fall outside the scope of this article, whose main objective directed the focus to describe the vignettes method. We will describe the items of each of the constructs in the following sections.

After the definition of the model, with the specification of the evaluation items for each construct, the second step consisted of creating the components of the scenarios that represented each of the items of the constructs, which were validated by an independent panel of ten experts. All have more than 5 years' experience in supervising and/or coordinating clinical services. These qualifications and experiences with health services position them as experts with adequate levels of knowledge about clinical situations to assess the quality of vignettes.

The vignettes were reviewed until there was agreement among the experts that the scenarios described clinical contexts of interactions between clients (patients) and front-line staff (physician, nurse, nurse practitioner, physiotherapist, etc.). In addition, the experts also reviewed the semantic correspondence between the components of the vignettes and the constructs reviewed by the literature. McCrow et al. (2013) used a cutoff of $90 \%$ agreement among experts to consider that there should be no changes in the textualization vignettes.

\subsection{DESCRIPTION OF CONSTRUCTS}

Table 1 presents the items of the constructs that we apply in this research.

Table 1. Constructs and their respective evaluation items.

\begin{tabular}{|c|c|c|c|}
\hline Flexibility & Co-innovation & Responsiveness & Co-creation \\
\hline F1 - Volume & I1 - Services & R1 - Dignity & $\mathrm{C} 1$ - Cooperation \\
\hline F2 - Reactivity & $\mathrm{I} 2-$ Scratch & R2 - Confidentiality & C2 - Information cataloging \\
\hline F3 - Expansion & I3 - Architecture & R3 - Autonomy & $\begin{array}{l}\text { C3 - Complementing } \\
\text { complementary therapies }\end{array}$ \\
\hline F4 - Communication & I4 - Value & R4 - Immediate attention & C4 - Learning together \\
\hline F5 - Routing & I5 - Customer base & R5 - Tangible aspects & C5 - Lifestyle changes \\
\hline \multirow[t]{3}{*}{ F6 - Function } & I6 - Business Models & $\begin{array}{l}\text { R6-Access to social } \\
\text { media support }\end{array}$ & C6 - Connectivity \\
\hline & & $\begin{array}{l}\text { R7 - Choice of service } \\
\text { provider }\end{array}$ & C7 - Coproduction \\
\hline & & & $\begin{array}{l}\text { C8 - Brain stimulation } \\
\text { workshops }\end{array}$ \\
\hline
\end{tabular}

Source: prepared by the authors. 
BBR

16,1

Since flexibility is a construct to deal with unforeseen changes, we should consider the system dynamics technology in the planning, forecasting, communication and implementation capabilities in its measurement (CHOU; CHUA, TEO, 2010; SCHNEEWEISS; SCHNEIDER, 1999).

Innovation through creativity is a dynamic process in which a person interacts with various factors within a social structure. That is, it results from a product of a social system, not merely the capacity of a person or a group of people (JACOBS, 2013). Thus, it becomes crucial to maintain a strong and sustainable competitive position to develop the ability to co-operate with other organizations (BOSSINK, 2002).

We can define responsiveness, in the context of a system, as the outcome that can be achieved when institutions and institutional relationships are designed to be able to respond adequately to people's legitimate and universal expectations (SILVA, 1999). Customer value co-creation is a benefit realized from the integration of resources through activities and interactions with employees in the customer service network (MCCOLL-KENNEDY et al., 2012).

\subsection{VignetTes: Scales ANd Affirmations}

Based on the review of the previous literature, we constructed four vignettes. Each of the vignettes represents a scenario associated to one of the four constructs of the structural model: flexibility (scenario 1); co-innovation (scenario 2); responsiveness (scenario 3); and, co-creation (scenario 4).

The scenarios represent situations of exsitu use, that is, they concern the seizure of information outside the situations of real use, retrospectively or in advance (EDVARDSSON et al., 2012) of the front-line staff (doctors, nurses, physiotherapists, technicians nursing, etc.). In relation to the context dimension, we can obtain information from the people who have been in contexto (EDVARDSSON et al., 2012). Respondents are familiar with context situations.

For each scenario, a set of statements (items) asks the respondent to report their level of approval or disapproval of each statement in the scenario. Thus, frontline employees are positioned, in this research, in the classification by Edvardsson et al. (2012), as reflective clients: they have experience in the real context of the service, but they are not experiencing a real situation of value creation.

A nine-point visual analogue scale measures the items. Analog visual scales produce results that are closer to a continuous measure (ERNSTGÅRD; BOTTAI, 2012). The grade of disapproval or approval on the visual analogue scale is graded from 1 (totally disapprove) to 9 (fully approve) (Figure 3). Numbering in the 1-5, 1-7, 1-9 or 1-11 format should be avoided because the sequence obscures the bipolar nature of the attribute for the respondent. We should always evaluate with a single item (ROSSITER, 2011).
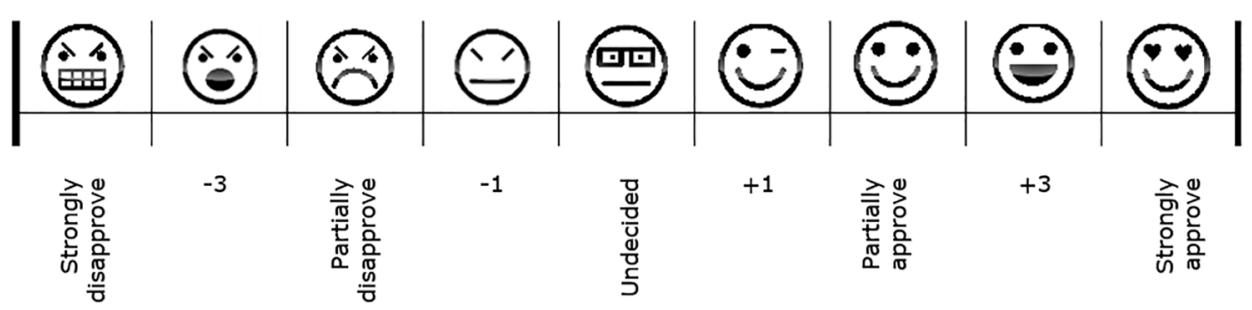

Figure 3. Visual analog scale. Source: prepared by the authors. 
The selection of statements should be such that people with different points of view regarding the attitude of interest in the survey respond in different ways (LIKERT, 1932). We must observe the following criteria in the construction of statements: (a) all statements should express desired behaviors, not statements about facts; (b) statements should be clear, concise and honest, with the simplest vocabulary possible; (c) in general, it would be desirable for the modal reaction of each statement to be averaged in relation to the possible responses; (d) statements must be in a bipolar distribution, so that half of the assertions are favorable and the other half unfavorable to the research attitude; (e) the different alternatives should refer to a single attitude, never to multiple attitudes.

We pre-tested the final questionnaire, composed of four vignettes and 27 items with representatives of the population of interest to verify the adequacy of the proposed model. The following is an illustration of the vignettes that represent the researched constructs and the evaluation checklist of the flexibility construct.

\section{RESULTS}

Regarding the content of the four constructs, there was $100 \%$ agreement among the experts about the appropriate context for the population of interest, indication of the behaviors of the client and the front-line staff, as well as indication of the communication between the front-line staff. After the adjustments indicated by the experts' observations, there was unanimity of agreement for the clarity, the simplicity and the correspondence between the domains of the four constructs. The four vignettes, from the perspective of all the experts, corresponded to the semantic meaning of the respective constructs. The following are the vignettes of the four researched constructs.

\subsection{VIGNETTE OF THE FLEXIBILITY CONSTRUCT}

Figure 4 illustrates the description of the vignette corresponding to the flexibility construct and its associated items. Figure 5 presents the final result of the panel of experts about this construct, and for the others the results are similar. Experts 1 to 4 (EXP1 ... EXP4), are physicians; those from 5 to 7 , nurses; and the 8 to 10, physiotherapists. In the second column (Figure 5) are the criteria for evaluating vignettes and their items, while in the latter there is the degree of agreement among the experts about content, clarity, simplicity, content validity and the analogy between vignette and the corresponding construct.

We can see flexibility, as a feature of the organization, under three conceptual components: employee skills, employee behavior, and the organization's human resource practices (BHATTACHARYA; GIBSON; DOTY, 2005). These characteristics are present, to some degree, in the concepts of items F5 (routing flexibility) and F6 (function flexibility) (Figure 4). These items describe, respectively, alternative routes for service delivery (responding to the visitor's intercurrence in the apartment instead of the client be moved to the emergency room) and capabilities of employees to perform new operations (the staff of the apartments, in hospitals, have specific operations directed to hospitalized clients).

Item F1 (Figure 4) refers to the temporary movement in a system to change its state in response to a variation in the demand for the service (the visitor demanded an unexpected service in the unit, so that the employees made a temporary move to attend to this demand), while item F2 refers to how fast the system performs this movement (employees attended quickly to the demand of the visitor, as opposed to a routine in which the customer could be moved to the first aid, demand the opening of an answer card and waiting to be answered). Employees, in this scenario, have not only demonstrated interest, as well as skills for temporary movement. 
BBR

16,1

26

The change in the routine of the professionals of the hospitalization unit (physiotherapist, doctor,

V1EF1 nurse, pharmacist, nursing technician and administrative assistant) was a good response to the intercurrence that happened to Ms. Sônia Alves's sister and to the image of the service.

V2三F2

The speed that the professionals of the hospitalization unit responded to the intercurrence was very important so that Ms. Sônia Alves's sister had a good experience and had a good image of the service.

V3三F3 Ms. Sonia Alves's sister was visiting her. The alignment among the professionals was important for the ease that the team attended this intercurrence.

The physiotherapist heard a need from Mrs. Sônia Alves's sister. He informed the nurse, who informed

V4EF4 the doctor. A decision was made and communicated to the pharmacy, the nursing technician, and the administrative assistant. This ability to communicate was important so that the intercurrence was well resolved.

The attendance of this event changes the routine of the hospitalization unit. Little adjustments in the

V5EF5 routine can allow Mrs. Sônia Alves's sister to be taken care of in the hospitalization unit, in addition to other places like the ambulatory or the emergency room.

The unit staff have well-defined functions in relation to hospitalized patients. But they can also be an

V6EF6 alternative to attend this event, in addition to other professionals from the ambulatory or the emergency room.

Figure 4. Example of vignette creation for the flexibility construct. Source: Silva (2014).

\begin{tabular}{|c|c|c|c|c|c|c|c|c|c|c|c|c|c|}
\hline \multicolumn{14}{|c|}{ Expert review results: vignette 1} \\
\hline \multirow{2}{*}{ R1 } & \multirow{2}{*}{ Content: plausible (typical and believable) } & \multicolumn{10}{|c|}{ To answer R1, use 1 for YES, 2 for NO or O for NOT APPLICABLE } & \multirow{2}{*}{\begin{tabular}{|c|} 
Total \\
answers \\
1 \\
\end{tabular}} & \multirow{2}{*}{$\%$} \\
\hline & & EXP01 & EXP02 & EXP03 & EXP04 & EXP05 & EXP06 & EXP07 & EXP08 & EXP09 & EXP10 & & \\
\hline \multirow{4}{*}{$\begin{array}{l}1.1 \\
1.2 \\
1.3 \\
1.4\end{array}$} & \multirow{4}{*}{$\begin{array}{l}\text { Context suitable for the population of interest } \\
\text { Customer behavior } \\
\text { Communication between front-line staff } \\
\text { Front-line staff behavior }\end{array}$} & \begin{tabular}{|l|l|}
1 & \\
\end{tabular} & 1 & 1 & 1 & 1 & \begin{tabular}{|l|l|}
1 & \\
\end{tabular} & 1 & 1 & 1 & 1 & 10 & 100 \\
\hline & & 1 & 1 & 1 & 1 & 1 & 1 & 1 & 1 & 1 & 1 & 10 & 100 \\
\hline & & 1 & 1 & 1 & 1 & 1 & 1 & 1 & 1 & 1 & 1 & 10 & 100 \\
\hline & & 1 & 1 & 1 & 1 & 1 & 1 & 1 & 1 & 1 & 1 & 10 & 100 \\
\hline \multirow{2}{*}{ R2 } & \multirow{2}{*}{ Clarity: not open to misinterpretation } & \multicolumn{10}{|c|}{ To answer R2, mark with $x$ the best suited alternative. } & \multirow{2}{*}{$\begin{array}{c}\text { Total } \\
\text { answers }\end{array}$} & \multirow{2}{*}{$\%$} \\
\hline & & EXP01 & EXP02 & EXP03 & EXP04 & EXP05 & EXP06 & EXP07 & EXP08 & EXP09 & EXP10 & & \\
\hline 2.1 & \multirow{3}{*}{$\begin{array}{l}\text { Limited clarity: needs revision } \\
\text { Moderate clarity: needs some revision } \\
\text { Good clarity: no revision needed }\end{array}$} & & & & & & & & & & & 0 & 0 \\
\hline 2.2 & & & & & & & & & & & & 0 & 0 \\
\hline 2.3 & & $x$ & $\mathrm{x}$ & $x$ & $x$ & $x$ & $x$ & $x$ & $\mathrm{x}$ & $x$ & $\mathrm{x}$ & 10 & 100 \\
\hline \multirow{2}{*}{ R3 } & \multirow{2}{*}{$\begin{array}{l}\text { Simplicity: easy to read and understand } \\
\text { information }\end{array}$} & \multicolumn{10}{|c|}{ To respond to R3, mark with $x$ the best suited alternative. } & \multirow{2}{*}{$\begin{array}{c}\text { Total } \\
\text { answers }\end{array}$} & \multirow{2}{*}{$\%$} \\
\hline & & EXP01 & EXP02 & EXP03 & EXP04 & EXP05 & EXP06 & EXP07 & EXP08 & EXP09 & EXP10 & & \\
\hline 3.1 & Too simplistic & & & & & & & & & & & 0 & 0 \\
\hline 3.2 & Too complex & & & & & & & & & & & 0 & 0 \\
\hline 3.3 & Adequate level of simplicity & $\mathrm{x}$ & $\mathrm{x}$ & $\mathrm{x}$ & $\mathrm{x}$ & $\mathrm{x}$ & $\mathrm{x}$ & $x$ & $\mathrm{x}$ & $\mathrm{x}$ & $\mathrm{x}$ & 10 & 100 \\
\hline \multirow{2}{*}{ R4 } & \multirow{2}{*}{$\begin{array}{l}\text { Validity of content: verify that the items } \\
\text { correspond to the domains of the construct }\end{array}$} & \multicolumn{10}{|c|}{ To answer R4, use 1 for YES, 2 for NO or O for NOT APPLICABLE } & \multirow{2}{*}{$\begin{array}{c}\text { Total } \\
\text { answers } \\
1\end{array}$} & \multirow{2}{*}{$\%$} \\
\hline & & \begin{tabular}{|l|} 
EXP01 \\
\end{tabular} & EXP02 & EXP03 & EXP04 & EXP05 & EXP06 & EXP07 & EXP08 & EXP09 & EXP10 & & \\
\hline 4.1 & Volume & \begin{tabular}{|l|}
1 \\
\end{tabular} & 1 & 1 & \begin{tabular}{|l|}
1 \\
\end{tabular} & 1 & \begin{tabular}{|l|}
1 \\
\end{tabular} & 1 & \begin{tabular}{|l|}
1 \\
\end{tabular} & 1 & 1 & 10 & 100 \\
\hline 4.2 & Reactivity & 1 & 1 & 1 & 1 & 1 & 1 & 1 & 1 & 1 & 1 & 10 & 100 \\
\hline 4.3 & Expansion & 1 & 1 & 1 & 1 & 1 & 1 & 1 & 1 & 1 & 1 & 10 & 100 \\
\hline 4.4 & Communication & 1 & 1 & 1 & 1 & 1 & 1 & 1 & 1 & 1 & 1 & 10 & 100 \\
\hline 4.5 & Routing & 1 & 1 & 1 & 1 & 1 & 1 & 1 & 1 & 1 & 1 & 10 & 100 \\
\hline 4.6 & Function & 1 & 1 & 1 & 1 & 1 & 1 & 1 & 1 & 1 & 1 & 10 & 100 \\
\hline \multirow{2}{*}{ R5 } & \multirow{2}{*}{$\begin{array}{l}\text { Analogy between the vignette and the } \\
\text { construct: compare if the vignette corresponds to } \\
\text { the semantic meaning of the construct }\end{array}$} & \multicolumn{10}{|c|}{ To answer R5, use 1 for YES, 2 for NO or O for NOT APPLICABLE } & \multirow{2}{*}{$\begin{array}{c}\text { Total } \\
\text { answers } \\
1\end{array}$} & $\%$ \\
\hline & & \begin{tabular}{|l|} 
EXP01 \\
\end{tabular} & EXP02 & EXP03 & EXP04 & EXP05 & EXP06 & EXP07 & EXP08 & EXP09 & EXP10 & & \\
\hline 5.1 & Vignette $1 \equiv$ Construct 1 & \begin{tabular}{|l|}
1 \\
\end{tabular} & \begin{tabular}{|l|}
1 \\
\end{tabular} & 1 & 1 & 1 & 1 & 1 & 1 & 1 & \begin{tabular}{|l|l|}
1 \\
\end{tabular} & 10 & 100 \\
\hline
\end{tabular}

Figure 5. Result of panel of experts on flexibility vignette. Source: Silva (2014). 


\subsection{VIGNETTE OF THE CO-INNOVATION, RESPONSIVENESS AND CO-CREATION CONSTRUCTS}

The innovation in services is a set of practices to create value for the stakeholders through improvements or new proposals, processes and service business models (YEN et al., 2012). In addition to paying attention to customer needs, it is also important to understand their preferences. The decision falls on a trade-off between risks and utilities, distinct between old and new customers (CHIU; LEUNG; LAM, 2009). Figure 6 presents the description of the hypothetical scenario associated with the co-innovation construct.

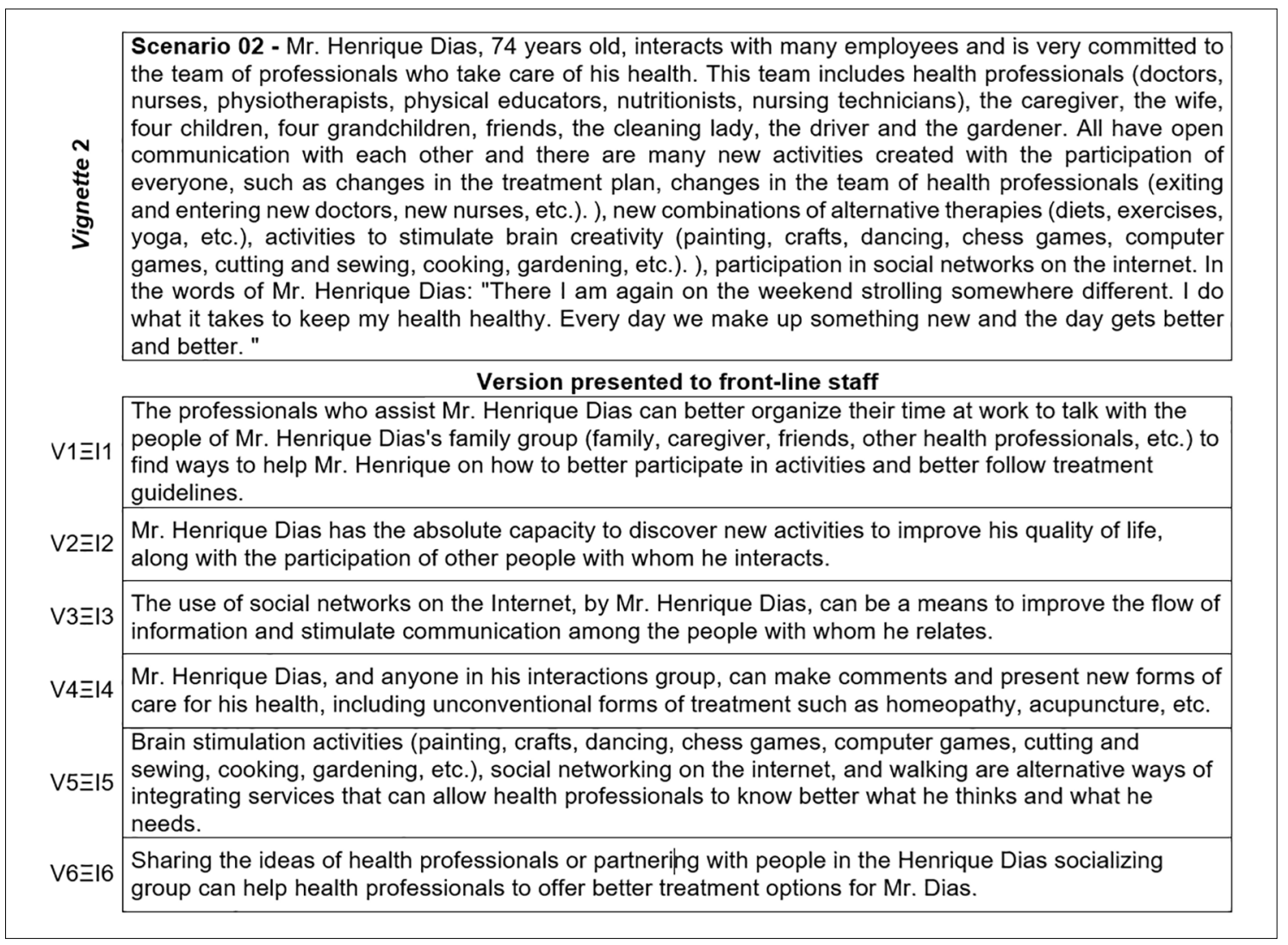

Figure 6. Example of vignette creation for the coinovation construct. Source: Silva (2014).

The construct is related to the user's perception of how health services deliver the elements that are not directly linked to the client's health or illness, for example, cleanliness of waiting places, offices, examination sites and restrooms (ANDRADE, VAITSMAN, FARIAS, 2010). Figure 7 presents the description of the hypothetical scenario associated with the construct responsiveness. Figure 8 presents the description of the hypothetical scenario associated to the co-construction construct.

The pre-test of the questionnaire, applied to a group of 15 individuals of the population of interest, revealed that the final textualization of the vignettes described realistic situations about the domains of interest of each construct. 
BBR

16,1

28

\section{Version presented to front-line staff}

Scenario 03 - Ana Maria is 67 years old and was hospitalized for a pneumonia treatment in the medical clinic ward. The forecast time for her hospitalization is 10 days. She has rheumatoid arthritis that compromises her joints in her arms and legs, so that it compromises her movements and caused her some bruises. In addition, she does not have a good control of the elimination of urine and feces. Because of her physical limitation, a chaperone remains full-time and provides support for food, clothing, bathing and personal hygiene. Her daughter can not visit her at the regular visit time, because she works $m$ during this time. The hospital staff allowed her to visit at a more convenient time. In daily activities, the nurse, when he wakes her up in the morning, greets her with a "good morning", asks how she spent the night, asks if the bed is comfortable, if the room temperature is pleasant or if there is something bothering her. When he applies the dressing on the bruises, the if the room temperature is pleasant or if there is something bothering her. When he applies the dressing on the bruises, the
nurse closes the curtains around Ana Maria's bed so that no one can see the procedure. Ana Maria talked to her doctor because of back pain. She has discussed with him alternative forms of treatment, such as special exercises, acupuncture, herbal treatment, lifestyle changes. The pain has increased in intensity, which led the doctor to adjust the dose of medication. The doctor also agreed to hear another doctor's opinion about the treatment. The doctor requested a series of blood tests, but she was resisting the collection. After some time, she agreed that the nurse involved in collecting the exams would do the procedure. After some time, the laboratory informs that the material had been insufficient for the examination to be done. The nurse asked Ana Maria if he could collect another blood sample.

$\mathrm{V} 1=\mathrm{R} 1$

By closing the curtains around Ana Maria's bed so that no one sees the apliances of the dressing, the nurse respects the client's privacy during the procedure.

V2=R2 Ana Maria has problems controlling the elimination of urine and feces. The presence of this full-time chaperone, giving support to the hygiene care, can protect her from conversations about prolonged bad odors in the infirmary.

V3=R3 Complementary exams are important to clarify the diagnosis. Even if the doctor asked for the exams, the nurse acted in an appropriate manner requesting permission to Ms. Ana Maria so that the exams were collected.

V4=R4 The team was very supportive in allowing Ana Maria's daughter to visit her at a time that suited her best. The hospital staff is facilitating access to information about the mother's hospitalization.

Comfort and hygiene of the beds are the competence of the hotel staff. A simple inspection and verification of the ambient

V5=R5 temperature are not enough for the nurse to see the conditions of comfort and cleanliness of the place. The nurse acted appropriately to ask if the conditions in the room were adequate for Ana Maria.

The stay of the companion of Ana Maria during the hospitalization, giving support to the personal care, such as, food,

V6=R6 clothing, bath, etc. contributes to a better recovery of Ana Maria. In addition, the companion has an opportunity to learn how to take better care of Ana Maria when they are at home.

The doctor's attitude in agreeing that Ana Maria discussed with him how to treat back pain and to consult the opinion of V7ER7 another doctor was very respectful. Ana Maria can receive the necessary information with clarity and simplicity and choose it together with her doctor, the best treatment option for her condition.

Figure 7. Example of vignette creation for responsiveness construct. Source: Silva (2014).

Scenario 04 - Cícero Almeida, 63, was diagnosed with a serious and fatal illness. The doctor talked to him about various types of treatment, medical and surgical, types of support available, as well as support from other medical specialties. $\checkmark \quad$ The doctor advised Cicero Almeida to take the medication immediately. Cicero Almeida, however, said he needed time E to think about whether he would take the medication and how it would affect his quality of life. The doctor said that would w be a great idea and that he could return next week for them to talk again about it. Cicero Almeida sought information with friends, relatives; he joined communities on the internet for patients with problems similar to his, visited religious communities. He started a list of activities and created a life project. He returned to the doctor after a week. Cicero Almeida, the family and the doctor decided together for a palliative treatment, in addition to alternative treatments. Everyone participated in the project of life and Cicero Almeida had an excellent quality of life experience.

\section{Version presented to front-line staff}

It was very important that the doctor explained what was happening to Cicero Almeida. The doctor's information helped V1EC1 Cícero Almeida to choose, along with the doctor and his family, which treatment option was best for him to have a better quality of life project.

Cícero Almeida acted well in creating a life project, with a list of activities to do, jotting down his daily activities, so that people can follow what he is doing, such as a blog, and a facebook page. Sharing his experience can inspire others.

$\mathrm{V} 3 \equiv \mathrm{C} 3$

Cicero Almeida's search by alternative treatments, such as, spiritual rituals, meditation, yoga, etc. and sharing with his medical staff can contribute to improving his quality of life.

Cícero Almeida's search for information in newspapers, magazines and the internet; listening to opinions from others,

V4=C4 including other doctors and other health professionals (nurses, physiotherapists, etc.) about his illness and discussing with them all, can help his life project provide him with a better quality of life

V5=C5 Changes in Cícero Almeida's lifestyle, such as routine at work, social routines, etc. to interact with new people and new situations will not change his prognosis but may bring improvements to his quality of life.

$V 6=C 6$ The entry of Cícero Almeida into networks of social relations, patient communities, communities on the internet, etc. to build and maintain new networks of relationships can bring improvements to his quality of life.

Cícero Almeida can choose the health professionals to take care of his health, to learn to choose the types of treatments,

$\mathrm{V} 7 \equiv \mathrm{C7}$ the duration of the treatment, etc| and, build and rebuild with the team the treatment plan that provides him with the best quality of life experience.

V7EC8 The participation of all, including Cicero Almeida to build his life project can bring new meanings and a unique experience for the quality of life.

Figure 8. Example of vignette creation for the co-creation construct. Source: Silva (2014). 


\section{FINAL CONSIDERATIONS}

This research aimed to review and describe criteria presented in the literature for a robust vignettes texturing. One of the main goals in the study of judgments and decision making directs the focus to identify the variables that influence the attitude of the service providers on the clients. For example, in the professional meeting of the health-client, it is important to understand how health professionals judge or make decisions about their clients (patients). Many of these studies are based on analogical research, in which the researcher controls the stimuli for the respondents.

Vignettes emerge as an analog research model in which the researcher controls the variables of interest so that we can omit or keep external factors constant. Nevertheless, the first draft of a vignette should be based on a review of the literature or on the judgment of experts, we recommend that a blind review be carried out to improve its validity and reliability.

The presence of DIF in surveys affects the effectiveness of the instruments, so the anchorage with vignettes is presented as a method to repair the measurement problems arising from the interpretation of the scales. Through the vignettes are added anchors in the questions seeking to achieve consistency in the answers and equivalence in the vignettes, allowing the respondent to position himself/herself comparatively to the status of the character.

This study presented some guidelines for the construction of vignettes with a view aimed at methodological rigor in relation to the validity and reliability of the data. A minimum set of criteria (plausibility, clarity, simplicity, content validity and analogy between the vignette and the construct) conceives the essential elements for the judicious development of this methodology. Nevertheless, we developed the application of the process in this study in scenarios involving health services, and since vignettes represent scenarios of real-life situations, it is useful to explore the application of the method in other areas of research, including in administration.

We developed the four hypothetical vignettes following the recommendations presented. A meticulous review of the literature on value creation attempted to make the content of the vignettes describe a real context of health services and thus built up a blueprint for the model. Experts evaluated textualized vignettes regarding the validation of the scenarios and the semantic equivalence of the vignettes, obtaining agreement superior to the recommended cutoff of $90 \%$.

As a theoretical contribution, this research looked at the recommendations on the design of research using the vignettes method. Thus, researchers will rely on a survey of criteria and recommendations for a robust textualization and application of a method to deal with DIF in surveys. In addition, the research explores a model on the background of the experience of value creation for a health service in order to illustrate the application of the method according to the criteria and recommendations presented. In practice, the results of this research contribute to increasing the knowledge about the creation of values in health services by proposing a pattern of development of operative resources that facilitates the creation of strategies to operationalize the concept of value creation with clients.

As the vignettes were applied to three different categories of professionals (physicians, physiotherapists and nurses) to express their opinion on the scenarios, one limitation of this research was the absence of hypothesis tests to verify if the perception of the scenarios diverges or does not due demographic differences and professional backgrounds. In this sense, surveys on attitudes are highly sensitive to textualization; the same questions may have different meanings for respondents when they are in different contexts. In addition, 
BBR

16,1

the theoretical and operational platform of this research does not explore the totality of constructs that potentially associate with the experience of value creation in health services.

Although this is a limitation, it also provides an opportunity to verify if there is in fact no difference of perception between the groups of respondents. It is also of interest to future research, the application and development of these criteria to improve the mechanisms for reducing the incomparability of data in interpersonal contexts.

\section{REFERENCES}

ANDRADE, G. R. B.; VAITSMAN, J.; FARIAS, L. O. Metodologia de elaboração do Índice de Responsividade do Serviço (IRS). Cad. saúde pública, v. 26, n. 3, p. 523-534, 2010.

ANDRADE, J. M.; LAROS, J. A.; GOUVEIA, V. V. O uso da teoria de resposta ao item em avaliações educacionais: diretrizes para pesquisadores. Aval. Psicol., v. 9, n. 3, p. 421-435, 2010.

ANDRIOLA, W. B. Descrição dos principais métodos para detectar o funcionamento diferencial dos itens (DIF). Psicologia: Reflexão e Crítica, v. 14, n. 3, p. 643-652, 2001.

BACHMANN, L. M. et al. Vignette studies of medical choice and judgement to study caregivers' medical decision behaviour: systematic review. BMC medical research methodology, v. 8, n. 1, p. 50, 2008.

BHATTACHARYA, M.; GIBSON, D. E.; DOTY, D. H. The effects of flexibility in employee skills, employee behaviors, and human resource practices on firm performance. Journal of Management, v. 31, n. 4, p. 622-640, 2005.

BOSSINK, B. A. G. The development of co-innovation strategies: stages and interaction patterns in interfirm innovation. R\&D Management, v. 32, n. 4, p. 311-320, 2002.

CHIU, D. K. W.; LEUNG, H.-F.; LAM, K.-M. On the making of service recommendations: An action theory based on utility, reputation, and risk attitude. Expert Systems with Applications, v. 36, n. 2, p. 3293-3301, 2009.

CHOU, M. C.; CHUA, G. A.; TEO, C.-P. On range and response: Dimensions of process flexibility. European Journal of Operational Research, v. 207, n. 2, p. 711-724, 2010.

CHRISTEN, M. et al. Using thesauruses as a heuristics for mapping values. Cognitive Systems Research, v. 40, p. 59-74, 2016.

COVA, B.; PARANQUE, B. Value slippage in brand transformation: a conceptualization. Journal of Product \& Brand Management, v. 25, n. 1, p. 3-10, 2016.

EDVARDSSON, B. et al. Customer integration within service development-A review of methods and an analysis of insitu and exsitu contributions. Technovation, v. 32, n. 7, p. 419-429, 2012.

ERNSTGÅRD, L.; BOTTAI, M. Visual analogue scales: how can we interpret them in experimental studies of irritation in the eyes, nose, throat and airways? Journal of Applied Toxicology, v. 32, n. 10, p. 777-782, 2012.

EVANS, S. C. et al. Vignette methodologies for studying clinicians' decision-making: Validity, utility, and application in ICD-11 field studies. International Journal of Clinical and Health Psychology, v. 15, n. 2, p. $160-170,2015$.

GANONG, L.; JAMISON, T.; CHAPMAN, A. Assessing differences in intimate partner obligations based on relationship status, gender, and parental status. J. Soc. Pers. Relat., p. 1-25, 2015.

GROL-PROKOPCZYK, H.; FREESE, J.; HAUSER, R. M. Using Anchoring Vignettes to Assess Group Differences in General Self-Rated Health. Journal of Health and Social Behavior, v. 52, n. 2, p. 246-261, 2011.

HEVERLY, M. A.; FITT, D. X.; NEWMAN, F. L. Constructing case vignettes for evaluating clinical judgment: an empirical model. Evaluation and Program Planning, v. 7, n. 1, p. 45-55, 1984.

HILTON, P. et al. Understanding variations in patient screening and recruitment in a multicentre pilot randomised controlled trial: a vignette-based study. Trials, v. 17, n. 1, p. 522, 2016.

JACOBS, H. Co-innovation through multiple social identity processes: the story of a South African co-op owned business. European Business Review, v. 25, n. 1, p. 42-64, 2013.

JOHNSON, R. M.; ORME, B. K. How many questions should I ask in choice-based conjoint studies. Sawtooth Software Research Papers, 1996.

KING, G. et al. Enhancing the validity and cross-cultural comparability of measurement in survey research. American political science review, v. 98, n. 1, p. 191-207, 2004. 
KING, G.; WAND, J. Comparing incomparable survey responses: Evaluating and selecting anchoring vignettes. Political Analysis, v. 15, n. 1, p. 46-66, 2007.

LANGER, P. C. The Research Vignette: Reflexive Writing as Interpretative Representation of Qualitative Inquiry--A Methodological Proposition. Qualitative Inquiry, v. 22, n. 9, p. 735-744, 2016.

LIKERT, R. A technique for the measurement of attitudes. Archives of psychology, 1932.

LOUVIERE, J. J.; EAGLE, T. C.; COHEN, S. H. Conjoint analysis: Methods, myths and much more. Documento de trabajo del Censoc, n. 5-1, p. 31, 2005.

MALHOTRA, N. K. Marketing research: An applied orientation. 5. ed. [s.1.] Prentice Hall, 2008.

MCCOLL-KENNEDY, J. R. et al. Health care customer value cocreation practice styles. J. Serv. Res., p. $1-20,2012$.

MCCROW, J. et al. Development and review of vignettes representing older people with cognitive impairment. Geriatr. Nurs., v. 34, n. 2, p. 128-137, 2013.

OREMUS, M.; XIE, F.; GAEBEL, K. Development of Clinical Vignettes to Describe Alzheimer's Disease Health States: A Qualitative Study. PloS one, v. 11, n. 9, p. e0162422, 2016.

ROSSITER, J. R. Measurement for the social sciences: The C-OAR-SE method and why it must replace psychometrics. 1. ed. New York: Springer-Verlag New York, 2011.

SCHNEEWEISS, C.; SCHNEIDER, H. Measuring and designing flexibility as a generalized service degree. European Journal of Operational Research, v. 112, n. 1, p. 98-106, 1999.

SILVA, A. S. Um modelo de antecedentes para a cocriação de valores em serviços de geriatria na cidade de São Paulo: uma aplicação da modelagem de equações estruturais. 2014. 277 f. Dissertação (mestrado em administração) - Universidade Municipal de São Caetano do Sul, São Caetano do Sul, 2014

SILVA, A. S. et al. A Model of Antecedents for the Co-Creation of Value in Health Care: An Application of Structural Equation Modeling. Brazilian Business Review, v. 12, n. 6, p. 121-149, 2015.

SILVA, A. DE. A framework for measuring responsiveness. Geneva: World Health Organization Geneva, 1999. (GPE Discussion Paper Series: No. 32)

VONKKOVÁ, H.; HULLEGIE, P. Is the anchoring vignette method sensitive to the domain and choice of the vignette? Journal of the Royal Statistical Society: Series A (Statistics in Society), v. 174, n. 3, p. 597-620, 2011.

WASON, K. D.; POLONSKY, M. J.; HYMAN, M. R. Designing Vignette Studies in Marketing. Australasian Marketing Journal, v. 10, n. 3, p. 41-58, 2002.

WINSOR, T.; MCLEAN, S. Residential group care workers' recognition of depression: Assessment of mental health literacy using clinical vignettes. Children and Youth Services Review, v. 68, p. 132-138, 2016.

YEN, H. R. et al. Service innovation readiness: Dimensions and performance outcome. Decis. Support Syst., v. 53, n. 4, p. 813-824, 2012.

ZHANG, C.; SIMON, J. C. An Empirical Investigation of Decision Making in IT-Related Dilemmas: Impact of Positive and Negative Consequence Information. Journal of Organizational and End User Computing (JOEUC), v. 28, n. 4, p. 73-90, 2016. 